\title{
Impacts of high-speed rail development on urban land expansion and utilization intensity in China
}

\author{
Xin Li \\ China University of Mining and Technology \\ topzcg@126.com
}

\author{
Xiaodong Ma \\ Jiangsu Normal University \\ 120256589@qq.com
}

\begin{abstract}
Urban land expansion (ULE) is a crucial factor for socioeconomic and environmentally sustainable development. However, nowadays, the unprecedented scale of high-speed railway (HSR) construction in China could exert an important influence on ULE. This manuscript first reveals the influence mechanism of HSR on ULE and then employs difference-in-difference (DID) models to investigate this effect based on the data of 280 prefectures and above level cities of 2001-2016. We analyze that HSR exerts a joint effect on ULE from the territorial and local levels and then affects urban land-use intensity (ULUI). HSR opening and HSR station distance both have notably positive effects on ULE, with elastic coefficients of $4.1 \%$ and $0.5 \%$, respectively. HSR opening and HSR station distance also both exert positive effects on ULE of the central, eastern region cities and large cities of China, while for the western region and small to medium cities, they are not significant. The impact of HSR station distance on ULUI is negative with a significance level of 0.073 , while the impact of HSR opening on ULUI is not significant. Lastly, relevant policy implications are proposed to alleviate urban land waste and spatial disequilibrium under the context of HSR building. This study can provide an important basis for sustainable urban land allocation.
\end{abstract}

Keywords: Urban land expansion, high-speed rail, influence mechanism, difference-in-difference model, urban land-use intensity, China

\section{Article history:}

Received: May 19, 2020

Received in revised form:

December 23, 2020

Accepted: February 22, 2021

Available online: May 11, 2021

\section{Introduction}

Urban land expansion (ULE) is the main path of human activities affecting global environment, especially for China, ULE determining the level of sustainable development, is a significant issue $(\mathrm{Qu}$, Heerink, \& Wang, 1995). As a main land cover change during the urbanization process, ULE encroaches on cultivated land, causing potential food crisis. Also ULE has a profound impact on biodiversity and carbon, hydrologic cycle, and specially, urban land produces about $70 \%$ of global greenhouse gas (Hopkins et al., 2016), and accounts for $80 \%$ of biodiversity loss on a local scale (Ke et al., 2018).

Copyright $2021 \mathrm{Xin} \mathrm{Li}$ and and Xiaodong Ma

http://dx.doi.org/10.5198/jtlu.2021.1804

ISSN: 1938-7849 | Licensed under the Creative Commons Attribution - Noncommercial License 4.0

The Journal of Transport and Land Use is the official journal of the World Society for Transport and Land Use (WSTLUR) and is published and sponsored by the University of Minnesota Center for Transportation Studies. 
For the following reasons, China's ULE exerts an overall and strategic impact on the national economic and social development, thus, ULE regulation is the core of the whole resource and environment policies. First, deducting the protected cultivated land and the ecological space, the space left for urban use is limited (China State Council, 2011). China has undergone rapid ULE during the past decades. According to statistics, urban built-up areas increased by $139.25 \%$ from 2001-2016, and such ULE rate is not sustainable (Wu, Luo, Zhang, \& Skitmore, 2016). Second, ULE is regarded as the engine of China economic growth, and is the main source of local fiscal revenue, therefore it can affect economic transition structure and quality (Lichtenberg \& Ding, 2009). Third, due to the incomplete land property right arrangement, ULE of China is excessive in terms of quantity, and brings unnecessary land resource waste (Tan, Qu, Heerink, \& Mettepenningen, 2011), manifested by the idle and inefficient urban utilization (Wu, Zhang, Skitmore, Song, \& Hui, 2014).

High-speed rail (HSR) construction exerts a complicated impact on urban spatial form, while nowadays China is constructing massive HSR. HSR greatly improves the temporal-spatial connection among cities (Jiao, Wang, Zhang, Jin, \& Liu, 2020), stimulates regional cities to expand spatially to the direction of interattraction, strengthens the spatial integration of regional cities, and provides conditions for the emergence of urban agglomeration (Wang, Wang, \& Liu, 2019). The first HSR line in China opened in 2008, and over the past 10 years, it experienced rapid development. The HSR mileage is projected to be $38,000 \mathrm{~km}$ at the year of 2025 (NDRC, 2016), and by the end of 2019, China has already constructed a HSR network with the mileage of 35,000 km. Due to the vast territory of China, HSR improves accessibility relatively great with its speed advantage. Additionally, China has huge population; and HSR can speed up industrial agglomeration, enhance urban image, and further promote the urbanization level; therefore, HSR is regarded as a good fit for the nation's characteristics and demand. HSR construction procedures from environmental impact assessment, corridors design to capital investment is dominated by governments in China. So construction speed is fast, with an average of 2,600 km per year in the past 10 years; however, if the socioeconomic and natural environment potential effects of HSR are inadequately understood and assessed, such large-scale, rapid construction may cause problems. Above all, due to the significant and profound influences of ULE on ecological environment and socioeconomic development, the impacts of HSR construction on ULE in China should be investigated urgently.

Existing literatures have studied HSR's impacts on urban development, and we review them from the following aspects. First, from the worldwide scope, with the opening of Japan's Shinkansen in 1964 and Europe's HSR in 1981, the impacts of HSR on urban development and land use begins to receive attentions. The impact of Spanish HSR on connected cities' ULE was studied and it was observed that accessibility improvement resulting from HSR was the direct impetus, and the impact was more obvious in big cities like Madrid and Seville than in other cities (Shen, De Abreu E Silva, \& Martínez, 2014; Shen, Martínez, \& De Abreu E Silva, 2013; Shen, Zhao, De Abreu E Silva, \& Martínez, 2017). Mohino, Loukaitou-Sideris, and Ureña (2014) asserted that 'ex-metropolitan' HSR station around metropolitan region caused urban development and achieve metropolitan integration. Ureña, Menerault, and Garmendia (2009) revealed the influence mechanism of HSR on urban development with a multilevel analysis at national, regional, and local levels, and Garmendia, Ribalaygua, and Ureña (2012) analyzed HSR's impact from two aspects: the new inter-city relationship brought by connectivity enhancement, and the station location of creating a new subcenter. HSR mostly impacted urban development in major node cities around the world (UIC, 2011), and researchers simulated it spatially with Cellular Automata models (Basse, 2013; Shen, Martinez, \& De Abreu E Silva, 2014). Second, for HSR's impacts in China, existing studies have examined the impacts on various aspects, such as tourism (Wang, Huang, Zou, \& Yan, 2012), housing price (Chen \& Haynes, 2015), urban accessibility (Jiao, Wang, \& Jin, 2017), 
industrial agglomeration (Shao, Tian, \& Yang, 2017), economic growth and $\mathrm{CO}_{2}$ emission (Chen, Xue, Rose, \& Haynes, 2016), and regional economic disparity (Chen \& Haynes, 2017). With regards to the impacts on urban growth, studies found regional HSR network affected the spatial morphology of urban agglomeration and guide cities to expand towards integration (Wang et al., 2019); some literatures also studied the urban morphology reshaping effects of HSR new town construction at suburban area (Chen \& Wei, 2013; Diao, Zhu, \& Zhu, 2016; Zheng, Long, Chang, \& Ye, 2019); some research analyzed the failure reasons of local governments creating new town based on the HSR station location, and proposed the place-based strategy aiming at promoting local economic by HSR station location (Deng, Gan, Perl, \& Wang, 2020; Dong, Du, Kahn, Ratti, \& Zheng, 2020); also, studies discovered that HSR facilitated the ULE (Long, Zheng, \& Song, 2018) and increased the fragmented land-use pattern in urban areas (Zhang, Zheng, Wu, Wang, \& Li, 2020). Finally, we comment that compared with the studies on regional and individual city scale, few studies explore the impact of currently massive HSR construction on ULE at the national level. Most of research pay attention on the urban development rather than ULE, and lack of the investigation on urban land-use intensity (ULUI). Besides, there is a lack of conceptual mechanism investigation of how HSR impacts ULE.

This research mainly has two innovations. First, we are from the perspective of land resource management to investigate the impacts of HSR opening and HSR station location on ULE and ULUI at the national level. Previous studies mainly focus on the impacts of HSR on urban development, while it is a synthetical concept including the increase of population, economic, urban land and so on, having a certain difference with ULE. Second, we establish a conceptual framework to describe the mechanism of HSR affecting ULE from the territorial level and local level. The remainder of this paper was organized as follows: Section 2 explored the influence mechanism of HSR on ULE from the territorial and local levels; Section 3 introduced the method and data description; Section 4 was the result analysis; and Section 5 presented the conclusion and policy implications.

\section{Influence mechanism of HSR on ULE}

HSR affects urban spatial layout and expansion direction through HSR station location, and also affects cities' status in regional urbans system through the improved accessibility (Ureña et al., 2009); thus, multilevel analysis is especially necessary to explore the impact of HSR on urban development. Similarly, the impact of HSR on ULE should be analyzed from multiple levels. Enlighted by the existing literature (Garmendia et al., 2012; Mohino et al., 2014; Ureña et al., 2009), influencing mechanism were jointly analyzed from the territorial and local levels following.

\subsection{Territorial level mechanism of HSR on ULE}

The territorial level mechanism of HSR on ULE refers to the improvement of city competitiveness from HSR that can attract production factors, such as investment and population, which require corresponding urban land to accommodate, and thus ULE is caused (Figure 1). The travel time between the cities HSR connects is drastically reduced; additionally, HSR has the advantages of acceptable fares, punctuality, multiple runs, and environmental friendliness (Diao, Fan, \& Zhang, 2019). Therefore, urban accessibility is improved significantly, which promotes the mobility of economic activities among cities (Wang, Du, \& Huang, 2020), reshapes regional urban pattern, and enhances urban competitiveness. It can optimize urban economic structure, make cities more modern and innovative, and improve urban images, all of which promotes the competitiveness of HSR cities (UIC, 2011). The improvement in urban competitiveness attracts investment and labor and facilitates the development of related industries 
(Harmon, 2006), which is the main reason why local governments strive for their cities to be connected by HSR. Because of the low time cost of visiting big cities and the convenience for information and technology exchange, companies and offices are inclined to choose HSR cities as sites (Willigers \& van Wee, 2011). In addition, HSR cities have gradually aggregated related industries (Li, Huang, Li, \& Zhang, 2016; Shao et al., 2017), generating the 'Marshall Effect' and 'Jacobs Effect' of reducing production cost of enterprise. China is now undergoing rapid population migration, and considerable ruralurban migration occurs, and more than 8 million graduates per year select the cities they will live. HSR means convenient external exchange, becoming a critical basis for individuals when choosing settled cities. Additionally, HSR can boost tertiary industries with preference for HSR, such as tourism, businesses, and banking. In summary, HSR brings about newly increased production factors, such as capital, population and technology that require additional urban land to accommodate, and thus leads to ULE.

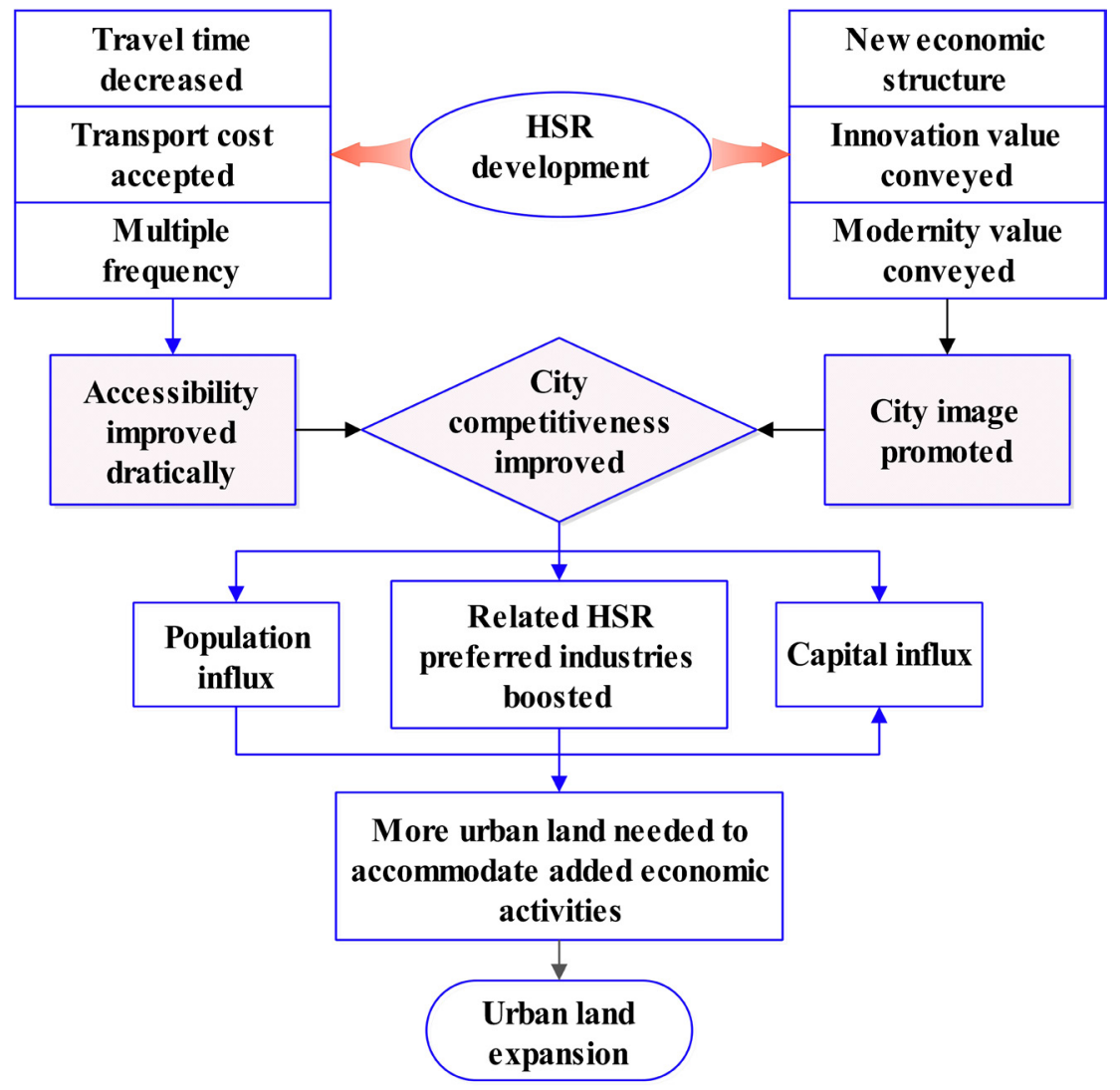

Figure 1. The territorial level mechanism flowchart of HSR on ULE

\subsection{Local level mechanism of HSR on ULE}

The affecting mechanism of HSR on ULE at local level refers to the following: vicinity development of HSR station gradually connect with downtown into a single stretch and finally leads to ULE. Most of HSR cities, except for several big cities such as Beijing, Shanghai, and Nanking, built HSR stations on the periphery of urban areas. The reasons for this type of setting are three folds. First, most Chinese cities are at rapid growth phrase, and station location is planned for the future urban morphology. Second, local governments of China have been actively accelerating ULE to grab land revenue and attract 
investment (Liu, Fan, Yue, \& Song, 2018), and during this process, HSR station location becomes a useful tool to pull urban expansion. Third, because of the rural collective property right arrangement in China, the compensation price of undeveloped land at outskirts is low by land expropriation (Tan et al., 2011), and development cost is also low without much remediation. Thus, taking HSR station as a stronghold, HSR cities built business, conference centers, hotels, and commercial residences to create new HSR towns in suburban areas. However, because of the long distance to downtown and insufficient ancillary facilities, their attraction for transfer of population and industries are limited (Yin, Bertolini, \& Duan, 2015); therefore, many are empty. The suburbanization of HSR station location leads to ULE in a leapfrog manner and neglects the convenience of intra-city access to HSR (Diao et al., 2016; Dong et al., 2020), which prolongs intra-city travel time to HSR station and offsets the time saving of HSR.

The local level mechanism can be explained vividly with the Alonso Bid-rent Model (Alonso, 1964). As urban center has the most prominent location, thus, its rent is the highest, from which to urban periphery, the rent decreases successively until it equals agricultural land rent, and accordingly, commercial, industrial, residential, and agricultural land are distributed successively from city center to periphery. In Figure $2, d_{0}$ is urban boundary. If $s$ is the location of an HSR station that is the impetus for the development of surrounding land, its rent increases and exceeds agricultural land rent. Therefore, $d_{3} d_{4}$ is converted into urban use for construction of, for example, hotels and conference centers. HSR generally improves city image and reduces transport cost, and these gains are transformed into the increased urban land rent, so decentralized population and employment occurs (Glaeser \& Kohlhase, 2003). That finally pushes the distance-rent curve up (Figure 2), specifically, urban boundary expanding to $d_{1}$, and boundary of HSR new town expanding from $d_{3} d_{4}$ to $d_{2} d_{5}$. Although $d_{1} d_{2}$ located between downtown and HSR station remains undeveloped, while under the dual and interactive impacts of the urban activities from both sides, it will be converted to non-agricultural use soon and eventually link the main city and HSR new town into a single stretch with low development intensity (Zheng et al., 2019). Thus, the suburbanization of HSR station results in urban leapfrog development, for which at least $d_{3} d_{4}$ is the excessive expansion part, and $d_{2} d_{3}$ and $d_{4} d_{5}$ are also likely to be avoided.

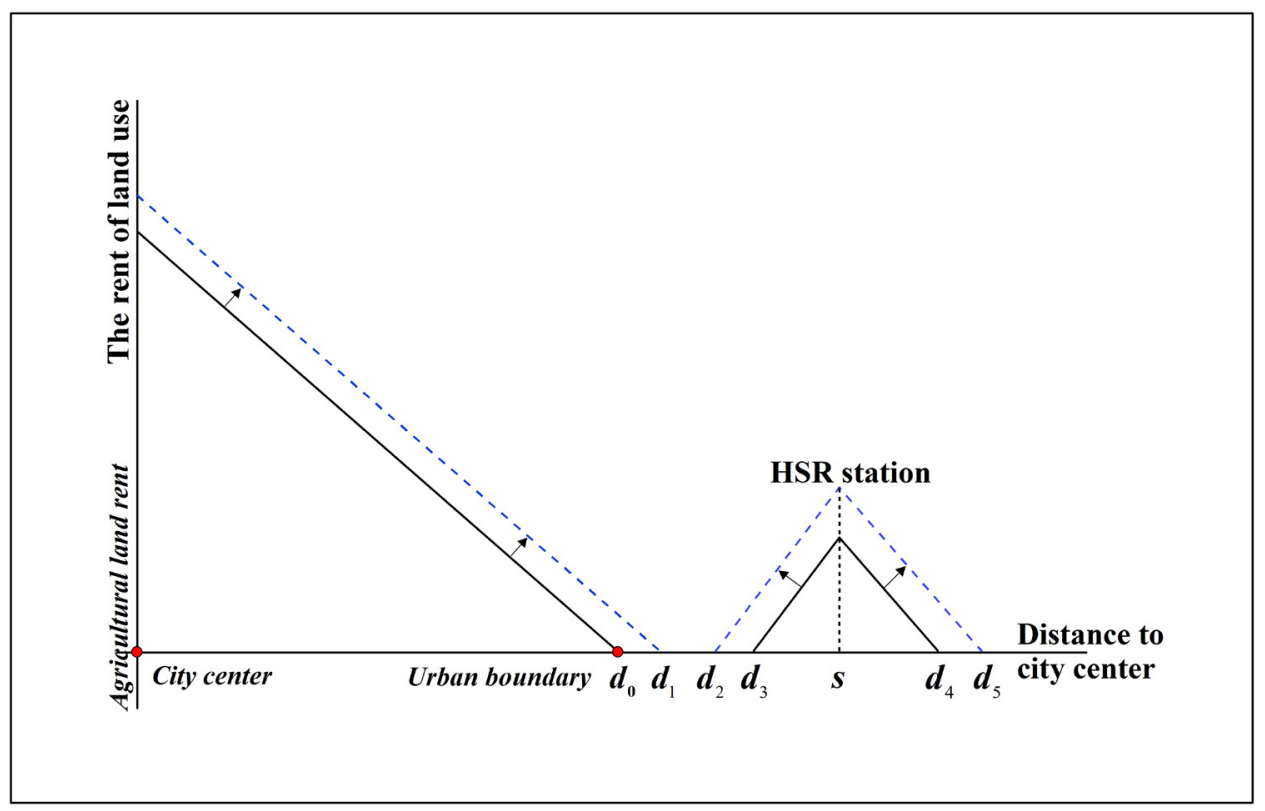

Figure 2. The affecting mechanism of HSR on ULE at the local level 
The territorial and local level mechanism of HSR on ULE are not parallel but interactive. For example, a good intra-city connection between HSR station and other traffic modes improves the efficiency of HSR. Additionally, HSR station design can further enhance urban image. All these factors promote urban competitiveness and impacts ULE from the territorial level. Additionally, accessibility improvement from territorial level influence HSR station location and HSR new town planning. If the ratio of population, capital, and other economic factors attracted by HSR to the newly expanded urban land accommodating these factors changes comparing with before, the variation of urban land-use intensity (ULUI) occurs. ULUI is the most important monitoring indicator of ULE regulation. Thus, in the following, the impact of HSR on ULUI was also tested.

\section{$3 \quad$ Methodology and data}

\subsection{Model description}

Investigating the impact of transport infrastructure on economic development or land use is difficult because they interact (Tranos, 2012). HSR can promote urban economic and urban development, while a city's GDP and size can also affect whether it can be connected by HSR. Thus, there is an endogeneity problem. Having considered this, we used difference-in-differences (DID) model. The DID model is widely used for exploring causal relationship and policy effects, and its main advantage is that it relaxes the assumption of conditional exogeneity and controls the interaction between dependent and independent variables effectively (Khandker, Koolwal, \& Sammad, 2010). Especially for panel data, DID model provides a tractable, intuitive way to account for the selection of unobserved characteristics; thus, relatively unbiased estimates can be obtained (Khandker et al., 2010). DID was adopted to estimate the effect of HSR on land price and industry agglomeration before (Chen \& Haynes, 2017; Shao et al, 2017); so, in this study, it was used to identify HSR effect on ULE and ULUI. DID essentially compares treatment and comparison groups before and after policy intervention to obtain the policy effect, and DID model with panel data was set as follows:

$Y_{i t}=\alpha_{0}+\beta_{0} H S R_{i t}+r Z_{i t}+\delta_{t}+f_{i}+\varepsilon_{i t}$

Where $Y_{i t}$ was the dependent variable of city $i$ at $t$ year, and the impacts of HSR on ULE and on ULUI were investigated. $H S R_{i t}$ was independent variable, where if there existed an HSR service in city $i$ at year $t, H S R_{i t}=1$; otherwise, $H S R_{i t}=0 . \beta_{0}$ was the estimator of HSR effect. $Z$ was the vector of control variables, and $r$ was the vector of their estimators. $\delta$ was the time fixed effect used to control time trend. $f$ was the individual fixed effect of controlling city heterogeneity. $\varepsilon$ signified the other unobserved characteristics that impacted ULE and ULUI.

According to Section 2, the distance from HSR station to downtown may impact ULE and ULUI, while traditional DID model can only consider the effect of presence or absence of HSR. Having considered this and learned from Shao et al. (2017) and Moser and Voena (2009), we established a continuous DID model-Equation 2 to investigate the impact of HSR station distance as follows:

$Y_{i t}=\alpha_{0}+\beta_{0}$ Stadis $_{i t}+r Z_{i t}+\delta_{t}+f_{i}+\varepsilon_{i t}$

Where Stadis $_{i t}$ referred to the distance from HSR station to city centre for city $i$; Stadis $_{i t}=0$ before HSR existence; after the emergence of HSR, it was a constant value; and $\beta_{0}$ was the effect of HSR station distance on ULE and ULUI, and meanings of the other symbols seen in Equation 1. 
HSR does not pass through cities randomly, for example, provincial capital cities and node cities are given priority. Fortunately, DID has some toleration for the selection bias that is time invariant, which is the so-called parallel-trend assumption that unobserved characteristics affecting programme participation do not vary over time. If there are important omitted variables, then their effect is put into unobserved heterogeneity and may violate the parallel-trend assumption and result in a biased estimation. Therefore, for model specification, control variables should be considered comprehensively to reduce endogeneity and selection bias. Two methods were employed to test the parallel-trend assumption here. One method was to test if the dependent variables of treatment and comparison groups had the same trend before HSR opening, which was widely used in existing literature (Khandker et al., 2010; Moser $\&$ Voena, 2009). Specifically, for the years before HSR opened, the interaction between treatment group and time variable were joined in Equation 1 to get Equation 3 as follows:

$$
\begin{aligned}
& Y_{i t}=\alpha_{0}+\sum_{k=2001-2007} \beta_{k} \text { Treat }_{i} \cdot \text { Pyear }_{\kappa}+\beta_{0} H S R_{i t}+r Z_{i t}+\delta_{t}+f_{i}+\varepsilon_{i t} \\
& Y_{i t, t=2001-2007}=\alpha_{0}+\beta_{0} H S R_{i t}+r Z_{i t}+\delta_{t}+f_{i}+\varepsilon_{i t}
\end{aligned}
$$

Where, if city $i$ belonged to treatment group, Treat $_{i}=1$, and when it was the $k$ th year, Pyear $_{k}=1$; otherwise, Pyear $_{k}=0$. If $\beta_{k}$ was not significant, treatment and comparison groups were believed to present the same trend before HSR opening. The second approach was a regression of Equation 4, which only used the data from 2001-2007 when HSR was not opened, while opening time was set 7 years earlier artificially. In this case, if HSR is still observed to affect ULE, indicating unobserved characteristics results in selection bias that is time variant and cannot be differenced off by $\delta_{t}$. Therefore, only if the two tests are passed can DID model fulfil the parallel-trend assumption.

\subsection{Variables specification}

The territorial level mechanism of HSR on ULE indicated that HSR could bring about the improvement of accessibility and city image, so as to attract capital, population and industries into cities. These needed additional urban land to accommodate, thus affecting ULE. So it can be seen that accessibility and city image improvement are important intermediary variables. Previous studies also confirmed that accessibility is the fundamental reason for the social and economic effects of HSR (Jiao et al., 2020; Wang et al., 2020), but here, according to above mechanism, the direct reason for ULE is urban factors variation, so urban population, GDP, infrastructure etc. were set as control variables in our DID models. The local level mechanism of HSR on ULE indicated that HSR station location was the main factor, therefore, when setting independent variables, in addition to HSR opening, HSR station distance to downtown was also set as an independent variable.

Specifically, for dependent variables, besides ULE, there was also ULUI, in Table 1. As ULUI is an important regulation indicator of ULE, central government allocates newly expanded urban land to cities according to their ULUI levels. Although Chinese government released related procedure for evaluating ULUI, it needed lots of data such as plot ratio, vacant land area, and the population corresponding to the urban land, etc. that are hard to obtain; so it was always simplified as per unit land GDP (Ministry of Land and Resources, 2008), and here, we did the same treatment. For control variables, since urban land is the carrier of economic activities and population, also GDP and population are the main indicators of measuring city size; thus urban population and the secondary and tertiary industry GDP were selected as partial control variables (Deng, Huang, Rozelle, \& Uchida, 2008). Urban green land was classified 
into urban construction land in China, and if it was omitted in modelling, an unobserved characteristic may result in biased estimation; thus, we chose it as control variable as well. Infrastructure construction is the main impetus for urban expansion, impacting urban land quantity and spatial morphology; thus, it was also set as control variable. The higher city level, the stronger economic agglomeration; thus, the drive effect on ULE is more obvious. According to GDP, we adopted the head-tail breaks method to rank city level (Jiang \& Ma, 2017), where if GDP ranked at the top $12.5 \%$, city level $=2$, and if GDP ranked between $12.5 \%$ and $25 \%$, city level $=1$; otherwise city level $=0$. Land-use intensity was proven to have close relationship with developing level (Peng, Song, \& Han, 2017). High developing level meant a strong economic output capacity of urban land which was commonly indicated by per capita GDP, and thus, it was chosen as a control variable. Additionally, average urban green space and urban infrastructure which were expected to have negative effect on ULUI, were also taken as control variables.

\subsection{Data Description}

The sample was 280 prefectural and above level cities of 2001-2016, and spatial domain was the municipal district. The urban land and other socioeconomic data were collected from the China City Statistical Yearbook. ULA is the data of Built District Area. The coordinates of the city centres and HSR stations were obtained from Baidu API (http://lbsyun.baidu.com/), that was, the locations of city centres were captured with the cityCenter function with Baidu API. To reduce heteroscedasticity, we performed a logarithmic treatment for all variables except for variable of HSR and CVEL. The definitions and descriptive statistics of variables are in Table 1.

Table 1. Marks and descriptive statistics of variables

\begin{tabular}{llllll}
\hline Variable & Mark & Mean & SD & Min. & Max. \\
\hline Urban land area $\left(\mathrm{km}^{2}\right)$ & ULA & 107.4 & 148.576 & 5 & 1420 \\
ULUI (million CNY/km²) & ULUI & 408.35 & 302.34 & 14.63 & 3675.38 \\
Whether HSR is opened or not & HSR & 0.21 & 0.41 & 0 & 1 \\
Distance from HSR station to down- & Stadis & 9286.34 & 12512.53 & 146.86 & 79944.57 \\
town (m) & & & & & \\
Urban population $(10000$ persons) & UP & 135.09 & 170.71 & 14.08 & 2449 \\
Second industry GDP (million CNY) & SGDP & 27513.13 & 52910.22 & 277.16 & 584000 \\
Third industry GDP (million CNY) & TGDP & 28230.8 & 77208.85 & 283.67 & 1340000 \\
Urban green space $\left(\mathrm{km}^{2}\right)$ & UGS & 54.96 & 132.4 & 0.27 & 1680.27 \\
Urban infrastructure area (km $\left.{ }^{2}\right)$ & UIA & 108.14 & 156.37 & 5 & 3371 \\
City level & CVEL & 0.1 & 0.39 & 0 & 2 \\
Average GDP (CNY/person) & AGDP & 33976.41 & 31837.23 & 1916 & 301875.2 \\
Average urban green space (m²/person) & AUGS & 37.24 & 52.71 & 0.23 & 1179.22 \\
Average urban infrastructure (m²/person) & AUIN & 85.18 & 162.33 & 64.02 & 10468.94 \\
\hline
\end{tabular}




\section{$4 \quad$ Results}

\section{1 $\quad 4.1$ Impacts on ULE}

\subsubsection{Robustness test}

In 3.1 Model description, two approaches were employed to test robustness. For HSR independent variable, robustness test results were in Columns 1-2 of Table 2, which were the regressions of Equation 3 and Equation 4. Interaction terms between treatment group and time variable were neither significant in Column 1, indicating treatment and comparison groups maintained the same ULE trend before HSR opening. In Column 2, only the data before HSR opened were used, namely, from 2001 to 2007, and the opening time was set 7 years earlier artificially. An insignificance level of HSR opening was 0.381 in Column 2, indicating no such selection bias, making the regression sample consistent with the parallel-trend assumption authentic. Similarly, for Stadis as independent variable, Columns 4-5 were regression results of Equation 3 and Equation 4. The interaction terms in Column 4 and the Stadis variable in Column 5 were not significant, making the regression results credible. Besides, in the following basic regressions, whether HSR or Stadis as independent variable, the impact was both significant. The above indicated the regression result was robust and the impact of HSR construction on ULE was not occasional.

\subsubsection{General impact}

In Table 2, Column 3 was the basic regression result of Equation 1, of which $\mathrm{R}^{2}$ was 0.867 , and HSR opening was observed having positive effect on ULE with a significance level of 0.067 . Ceteris paribus, cities with HSR expanded by $4.1 \%$ more than cities without HSR regarding urban land in China, while Long, Zheng, \& Song, 2018 found that the elasticity is approximately $12 \%-13 \%$. There were two reasons for this disparity. The first was data difference: their urban land was obtained from remote images of $1 \mathrm{~km} \times 1 \mathrm{~km}$, including construction land of the whole city rather than only the city proper. The second was the control variables' difference of modelling, making the effects of some unobserved factors be mistaken for the HSR's effect. According to the above territorial level mechanism on ULE, HSR can improve accessibility drastically, reduce transportation cost, and promote city image. These factors attract population, investment, tourism, and other related industries ( $\mathrm{Li}$, Strauss, Shunxiang, \& Lui, 2018), which require new urban land to support and finally drives the general ULE in HRS cities. Moreover, the central government provides HSR-connected cities with more urban land quotas in land-use planning; thus, the planning constraint for ULE of these cities is relatively small. For control variables, the impacts of GDP, population, urban green space, infrastructure, and city level were all positive at the $1 \%$ significance level, among which, the contribution rate of urban population was the greatest, with $28.39 \%$, and that of GDP and urban infrastructure were $19 \%$ and $15.9 \%$, respectively. 
Table 2. Regression results of HSR impact on ULE in China

\begin{tabular}{|c|c|c|c|c|c|c|}
\hline \multirow{2}{*}{ Variables } & \multicolumn{6}{|c|}{ Dependent variable: $U L A$} \\
\hline & (1) & (2) & (3) & (4) & (5) & (6) \\
\hline$H S R$ & $\begin{array}{l}0.034 \\
(1.77)^{*}\end{array}$ & $\begin{array}{l}0.023 \\
(0.88)\end{array}$ & $\begin{array}{l}0.041 \\
(2.14)^{* *}\end{array}$ & & & \\
\hline Stadis & & & & $\begin{array}{l}0.004 \\
(2.03)^{* *}\end{array}$ & $\begin{array}{l}0.002 \\
(0.76)\end{array}$ & $\begin{array}{l}0.005 \\
(2.35)^{* *}\end{array}$ \\
\hline$T G D P$ & $\begin{array}{l}0.100 \\
(4.51)^{* * *}\end{array}$ & $\begin{array}{l}0.147 \\
(2.78)^{* * *}\end{array}$ & $\begin{array}{l}0.099 \\
(4.54)^{* * *}\end{array}$ & $\begin{array}{l}0.099 \\
(4.47)^{* * *}\end{array}$ & $\begin{array}{l}0.148 \\
(2.79)^{* * *}\end{array}$ & $\begin{array}{l}0.099 \\
(4.50)^{* * *}\end{array}$ \\
\hline$S G D P$ & $\begin{array}{l}0.087 \\
(3.54)^{* * *}\end{array}$ & $\begin{array}{l}0.097 \\
(2.44)^{* *}\end{array}$ & $\begin{array}{l}0.091 \\
(3.95)^{* * *}\end{array}$ & $\begin{array}{l}0.087 \\
(3.55)^{* * *}\end{array}$ & $\begin{array}{l}0.097 \\
(2.46)^{* *}\end{array}$ & $\begin{array}{l}0.091 \\
(3.94)^{* * *}\end{array}$ \\
\hline$U P$ & $\begin{array}{l}0.283 \\
(4.43)^{* * *}\end{array}$ & $\begin{array}{l}0.206 \\
(2.06)^{* *}\end{array}$ & $\begin{array}{l}0.284 \\
(4.43)^{* * *}\end{array}$ & $\begin{array}{l}0.282 \\
(4.41)^{* * *}\end{array}$ & $\begin{array}{l}0.206^{* *} \\
(2.05)^{* *}\end{array}$ & $\begin{array}{l}0.283 \\
(4.42)^{* * *}\end{array}$ \\
\hline UGS & $\begin{array}{l}0.102 \\
(4.65)^{* * *}\end{array}$ & $\begin{array}{l}0.062 \\
(1.92) *\end{array}$ & $\begin{array}{l}0.102 \\
(4.66)^{* * *}\end{array}$ & $\begin{array}{l}0.102 \\
(4.64)^{* * *}\end{array}$ & $\begin{array}{l}0.062 \\
(1.93)^{*}\end{array}$ & $\begin{array}{l}0.102 \\
(4.65)^{* * *}\end{array}$ \\
\hline UIA & $\begin{array}{l}0.158 \\
(5.72)\end{array}$ & $\begin{array}{l}0.137 \\
(4.71)^{* * *}\end{array}$ & $\begin{array}{l}0.159 \\
(5.76)^{* * *}\end{array}$ & $\begin{array}{l}0.158 \\
(5.72)^{* * *}\end{array}$ & $\begin{array}{l}0.137 \\
(4.71)^{* * *}\end{array}$ & $\begin{array}{l}0.159 \\
(5.76)^{* * *}\end{array}$ \\
\hline CVEL & $\begin{array}{l}0.066 \\
(3.12)^{* * *}\end{array}$ & $\begin{array}{l}0.088 \\
(0.82)\end{array}$ & $\begin{array}{l}0.067 \\
(3.19)^{* * *}\end{array}$ & $\begin{array}{l}0.065 \\
(3.10)^{* * *}\end{array}$ & $\begin{array}{l}0.089 \\
(0.83)\end{array}$ & $\begin{array}{l}0.067 \\
(3.17)^{* * *}\end{array}$ \\
\hline Treat ${ }^{*} 2001$ & $(-0.79)$ & & & $(-0.75)$ & & \\
\hline Treat*2002 & $(-0.79)$ & & & $(-0.74)$ & & \\
\hline Treat ${ }^{*} 2003$ & $(0.06)$ & & & $(0.12)$ & & \\
\hline Treat*2004 & $(-0.24)$ & & & $(-0.18)$ & & \\
\hline Treat ${ }^{*} 2005$ & $(-0.65)$ & & & $(-0.58)$ & & \\
\hline Treat*2006 & $(-1.64)$ & & & $(-1.53)$ & & \\
\hline Treat ${ }^{*} \mathbf{2 0 0 7}$ & $(-1.51)$ & & & $(-1.37)$ & & \\
\hline $\mathbf{R}^{2}$ & 0.866 & 0.845 & 0.867 & 0.867 & 0.845 & 0.867 \\
\hline Observations & 4480 & 1960 & 4480 & 4480 & 1960 & 4480 \\
\hline
\end{tabular}

Note: ${ }^{*},{ }^{* *}$, and ${ }^{* * *}$ represent significances at the $10 \%, 5 \%$, and $1 \%$ level, respectively; $T$ values are in parentheses; the same meanings in the following tables.

Based on the above robustness tests, Column 6 was the basic regression result of Equation 2, and it tested that HSR station distance exerted a positive effect on ULE with a significance level of 0.05 . That was, the farther away HSR station location was from downtown, the more obvious ULE effect was. Additionally, ULE increased by $0.5 \%$ for every $1 \%$ increase of HSR station distance from downtown. HSR station can stimulate the development of surrounding areas. Thus, local governments supported building HSR new town between which and downtown the area had convenient access to both sides, therefore was developed gradually into a continuous stretch (Zheng et al., 2019). Additionally, HSR new town is planned as city subcenter around which city begins a new expansion. For 179 HSR-connected cities, the average Built District Area of 2016 was $193.23 \mathrm{~km}^{2}$; thus, coarsely, the average radius of these cities was $7.88 \mathrm{~km}$, while their average HSR station distance was $9.59 \mathrm{~km}$, so most HSR station obviously located at the periphery. This confirmed the aforementioned local level mechanism, HSR station was taken as a supporting point for urban leapfrog development; thus, HSR station distance to downtown can influence the ULE. 


\subsubsection{Heterogeneity of HSR impact on ULE}

We further investigated the difference of HSR effect on ULE among different regions and different types of cities. The regression results were in Table 3, where the estimation of control variables were not displayed. We observed that for the eastern and central cities of China, HSR opening had positive impact on ULE with elastic coefficients of 0.063 and 0.071 , indicating that in eastern and central cities HSR can attract additional factors that required new urban land to accommodate, and thus, it drove ULE. Ceteris paribus, HSR cities expanded by $6.3 \%$ and $7.1 \%$ more than cities without HSR regarding urban land in the eastern and central cities, respectively. However, for western cities in China, the effect of HSR opening on ULE was insignificant, which may be because although HSR improved accessibility and connectivity drastically, the western cities' development level was low; thus, having not attracted enough growth factors compared with eastern and central cities, even because of HSR opening, population outflow was aggravated. The cities ranked in the top $12.5 \%$ of GDP are defined as big cities and other cities are defined as small- and medium-sized cities. The results showed that for big cities, the effect of HSR opening on ULE was significant at $1 \%$ level with a coefficient of 0.101 . For the small- and medium-sized cities, it was not significant, which is similar to the result of Shen et al. that the impetus of Spanish HSR on urban growth was more obvious in big cities than in small cities (Shen et al., 2013). This may be because accessibility of big cities was improved drastically with frequent HSR runs (Jiao et al., 2017), and just due to the emergence of HSR, big cities attracted population, capital, and other economic factors from other cities more conveniently than before by their advantages (Wang et al., 2016). That is, the so-called Matthew effect aggravated with HSR opening during regional competition, makes big cities grow significantly and small- and medium-sized cities not obvious.

Table 3. Regression results of HSR on ULE for different regions and types of cities

\begin{tabular}{llllll}
\hline \multirow{2}{*}{ Variables } & \multicolumn{4}{c}{ Dependent variable: $\boldsymbol{U L A}$} \\
\cline { 2 - 6 } & Eastern cities & Central cities & Western cities & Big cities & Small- and medium-sized cities \\
\hline $\boldsymbol{H}$ HSR & 0.063 & 0.071 & -0.034 & 0.101 & 0.019 \\
& $(1.91)^{*}$ & $(2.71)^{* * *}$ & $(-0.80)$ & $(3.05)^{* * *}$ & $(0.84)$ \\
\multirow{2}{*}{ Stadis } & 0.009 & 0.009 & -0.003 & 0.012 & 0.026 \\
& $(2.48)^{* *}$ & $(3.04)^{* * *}$ & $(-0.67)$ & $(3.24)^{* * *}$ & $(0.95)$ \\
Observation & 1584 & 1616 & 1280 & 1120 & 3360 \\
\hline
\end{tabular}

The same results were observed when independent variable Stadis was adopted, and for the eastern, central cities and big cities, HSR station distance exerted positive effect on ULE at the significance level of $5 \%$ and above, while for the western cities and small- and medium-sized cities, it was insignificant. The possible reason is that the growth of western cities and small- and medium-sized cities lacks impetus, and growth factors do not tend to flow into them (Wang et al., 2016); even if HSR station is taken as spatial instrument for urban leapfrog development by local governments, this tendency is not changed. As Deng et al. (2020) analysed that the demand of economic, population and employment growths were prerequisites for HSR station surrounding development, and HSR station should not be solely understood as an impetus for urban development. Thus, for western and small- and mediumsized cities, the impact of HSR station location on ULE was not significant, due to the lack of other driving factors. 


\subsection{Impacts on ULUI}

ULE is inevitable during the rapid urbanisation and industrialisation processes; however, for ULE regulation, the basic standard is that ULUI remains unchanged or increases; thus, we also investigated the impacts of HSR on ULUI.

\subsubsection{Robustness test}

In Table 4, Columns 1-2 tested the parallel-trend assumption jointly. Similarly, taking Stadis as independent variable, Columns 4-5 were the regression of Equation 3 and Equation 4. Although in Column 4, the interaction term of 2006 year was significant, other interaction terms and the Stadis variable in Column 5 were not significant; indicating treatment and comparison groups maintained the same ULUI trend before HSR opening, and there was no selection bias. Thus, we generally considered the parallel-trend assumption was fulfilled and the following basic regression results were robust.

\subsubsection{General impact}

In Table 4, Column 3 was the basic regression result of Equation 1 to test the impact of HSR opening on ULUI, and it indicated that HSR opening had negative effect on ULUI but was not significant. Column 6 was the basic regression with Stadis as independent variable to investigate the impact of HSR station distance on ULUI. We observed that Stadis had a negative effect on ULUI, with significance level of 0.073 , that was, the farther away HSR station was from downtown, the lower ULUI would be, implying land resource waste occurring. This is because under the arrangement of related financial policies, more urban land means more assets and a larger GDP number; thus, local governments are proactive to increase land asset reserve (Liu, Fan, Yue, \& Song, 2018). The location of HSR station was then taken as a wedge for urban development, and the land between HSR station and downtown, and peripheral land around HSR station would be developed gradually; however, there were not enough population, capital and industries to occupy these land (Zheng, Long, Chang, \& Ye, 2019). Because land resources are state-owned, why not make it into urban asset with the opportunity of HSR opening. Although central government always motivated local governments to promote ULUI, however, there was little criterion in current officials' achievement appraisal. Particularly, with such a land factor-driven style of urbanisation and industrialisation in China, reducing land resources' input means losing development impetus and opportunity; thus, local governments were not enthusiastic about ULUI enhancement, but having desires to expand urban land (Shu, Xie, Jiang, \& Chen, 2018). Therefore, HSR station distance exerted a negative effect on ULUI significantly in China. 
Table 4. Regression results of HSR impact on ULUI of 2001-2016 in China

\begin{tabular}{|c|c|c|c|c|c|c|}
\hline \multirow{2}{*}{ Variables } & \multicolumn{6}{|c|}{ Dependent variable: $U L U I$ and its inverse } \\
\hline & (1) & (2) & (3) & (4) & (5) & (6) \\
\hline$H S R$ & $\begin{array}{l}-0.011 \\
(-0.60)\end{array}$ & $\begin{array}{l}0.012 \\
(0.49)\end{array}$ & $\begin{array}{l}-0.009 \\
(-0.48)\end{array}$ & & & \\
\hline Stadis & & & & $\begin{array}{l}3.32 \mathrm{E}-05 \\
(1.54)\end{array}$ & $\begin{array}{l}-7.46 \mathrm{E}-06 \\
(-0.26)\end{array}$ & $\begin{array}{l}3.32 \mathrm{E}-05 \\
(1.80)^{*}\end{array}$ \\
\hline$A G D P$ & $\begin{array}{l}0.804 \\
(26.08)^{* * *}\end{array}$ & $\begin{array}{l}0.687 \\
(14.13)^{* * *}\end{array}$ & $\begin{array}{l}0.804 \\
(28.68)^{* * *}\end{array}$ & $\begin{array}{l}-7.65 \mathrm{E}-03 \\
(-23.99)^{* * *}\end{array}$ & $\begin{array}{l}-6.89 \mathrm{E}-03 \\
(-13.84)^{* * *}\end{array}$ & $\begin{array}{l}-7.65 \mathrm{E}-03 \\
(-26.50)^{* * *}\end{array}$ \\
\hline$A U G S$ & $\begin{array}{l}-0.113 \\
(-5.11)^{* * *}\end{array}$ & $\begin{array}{l}-0.113 \\
(-1.98)^{* *}\end{array}$ & $\begin{array}{l}-0.113 \\
(-5.07)^{* * *}\end{array}$ & $\begin{array}{l}9.60 \mathrm{E}-04 \\
(4.36)^{* * *}\end{array}$ & $\begin{array}{l}5.95 \mathrm{E}-04 \\
(1.68)\end{array}$ & $\begin{array}{l}9.57 \mathrm{E}-04 \\
(4.33)^{* * *}\end{array}$ \\
\hline AUIN & $\begin{array}{l}-0.170 \\
(-5.48)^{* * *}\end{array}$ & $\begin{array}{l}-0.113 \\
(-4.30)^{* * *}\end{array}$ & $\begin{array}{l}-0.168 \\
(-5.44)^{* * *}\end{array}$ & $\begin{array}{l}1.59 \mathrm{E}-03 \\
(5.13)^{* * *}\end{array}$ & $\begin{array}{l}1.22 \mathrm{E}-03 \\
(3.97)^{* * * *}\end{array}$ & $\begin{array}{l}1.57 \mathrm{E}-03 \\
(5.10)^{* * *}\end{array}$ \\
\hline Treat ${ }^{*} 2001$ & $(-1.37)$ & & & $(0.82)$ & & \\
\hline Treat*2002 & $(-0.83)$ & & & $(0.29)$ & & \\
\hline Treat*2003 & $(-1.38)$ & & & $(0.65)$ & & \\
\hline Treat*2004 & $(-0.82)$ & & & $(0.07)$ & & \\
\hline Treat*2005 & $(-0.17)$ & & & $(-0.43)$ & & \\
\hline Treat*2006 & $(0.68)$ & & & $(-1.69)^{*}$ & & \\
\hline Treat*2007 & $(0.70)$ & & & $(-1.56)$ & & \\
\hline $\mathbf{R}^{2}$ & 0.693 & 0.587 & 0.691 & 0.649 & 0.561 & 0.647 \\
\hline Observation & 4480 & 1960 & 4480 & 4480 & 1960 & 4480 \\
\hline
\end{tabular}

\subsubsection{Heterogeneity of HSR impact on ULUI}

Results in Table 5 indicated that the effect of HSR opening on ULUI for different regions and types of cities were not significant. However, we observed that for the central region cities and small cities, HSR station distance had negative effect on ULUI at a significance level of 5\%, and for every $1 \%$ moving outward of HSR station location, the inverse of ULUI increased by $7.18 \%$ and $11.8 \%$, respectively. This is because China has a stepwise development pattern from the eastern, central to western region, and nowadays, the strategy of central region rising is implemented by central government to reduce regional disparity. To support this strategy, central government provided biased policies for central cities regarding urban land quotas (China State Council, 2016), and the location of HSR station was just right taken as a spatial instrument of urban expansion by local governments. Therefore, for central cities, the farther HSR station distance, the more urban land newly expanded, and the lower the ULUI was. Compared with big cities, because of lack of driving forces, small cities were more dependent on HSR station location with respect to ULE. The ability of factor conglomeration of big cities was higher than that of small cities (Wang et al., 2016), and they did not completely depend on HSR station location to drive urban growth; therefore, HSR station distance exerted negative effect on ULUI only for small cities. 
Table 5. Regression results of HSR on ULUI for different regions and types of cities

\begin{tabular}{llllll}
\hline \multirow{2}{*}{ Variables } & \multicolumn{5}{c}{ Dependent variable: $U L U I$ and its inverse } \\
\cline { 2 - 6 } & Eastern cities & Central cities & Western cities & Big and medium cities & Small cities \\
\hline HSR & -0.034 & -0.043 & 0.034 & -0.034 & 0.017 \\
& $(-0.12)$ & $(-1.54)$ & $(0.85)$ & $(-1.18)$ & $(0.69)$ \\
Stadis & $2.56 \mathrm{E}-05$ & $7.18 \mathrm{E}-05$ & $9.87 \mathrm{E}-06$ & $5.17 \mathrm{E}-06$ & $1.18 \mathrm{E}-04$ \\
& $(0.85)$ & $(2.14)^{* *}$ & $(-0.20)$ & $(0.23)$ & $(2.27)^{* *}$ \\
Observation & 1584 & 1616 & 1280 & 3136 & 1344 \\
\hline
\end{tabular}

\section{$5 \quad$ Policy implication and conclusion}

\subsection{Policy implication}

This paper proposes three policy implications. First, for central government, the impacts of HSR on ULE and ULUI should be considered during the new urban land allocation of planning. Under the same condition, HSR cities should be provided with more urban land quota. Moreover, HSR as a modern mode of transportation can bring advanced factors such as technology and information and promote industrial upgrading and agglomeration; thus, it is supposed to improve ULUI. However, we observed that for the central region cities and small cities, HSR station distance exerted a negative effect on ULUI, which should be regulated emphatically. Therefore, the accuracy of urban land allocation should be improved to prevent land resource waste caused by HSR station location under the pretext of HSR building. Second, locations of HSR stations should be determined based on the convenience and fairness of intercity traffic for citizens and the rationality of HSR line route (Chen \& Wei, 2013), rather than solely taken as a spatial supporting point for ULE. Thus, public participation should be adopted for the site selection of HSR station, rather than only decided by government. HSR stations are better located within urban range, and the maximum location distance should be set according to the planning radius of cities (Yin et al., 2015). Additionally, blind overdevelopment of HSR new towns should be restricted to avoid "ghost town." Local governments should be guided scientifically how to use HSR station location to boost local economic. Third, regional imbalance owing to HSR development should be paid attention (Chen \& Haynes, 2017). Although China is now attempting to pursue a balanced spatial pattern of urbanization, HSR results in Matthew effect such that population, industries, and other factors are attracted to flow into big cities and east-central cities (Wang et al., 2016), which is an efficient phenomenon from the view of economics; however, an excessive Matthew effect will lead to unbalanced development and inequity. Thus, for big cities, some functions should be transferred to generate a spillover effect and for western cities and small cities, their distinctive development paths should be guided. Additionally, public service facilities should be allocated equally for different regions and cities to cope with the possible regional imbalances.

\subsection{Discussion and conclusion}

Although ULE is a common land cover change during urbanization process, it exerts a strategic impact on the sustainable development of socioeconomic and ecology. Additionally, China's ULE is typically of government-driven and plays a critical role in China's economic growth mode, and all these characteristics indicate that China's ULE is complicated and crucial. Nowadays, the largest ever HSR development 
in China is occurring, thus this paper investigated its impact on ULE and utilisation. We first analysed the influence mechanism of HSR on ULE from the territorial and local levels. Next, DID model taking 280 cities of 2001-2016 as sample was employed to examine HSR impact; as well the difference of this effect on different regions and types of cities was studied. The main challenge of this study lies in the identification of HSR impacts on ULE and ULUI from various influence factors relative accurately. For it, we adopted 2 measures, one side, the possible control variables such as population, GDP, infrastructure and so on, were taken into DID model to remove their disturbance, and the other side, the parallel-trend assumption was employed to remove the effects of unobserved invariant factors. The major findings were summarised as follows: (1) HSR impacted ULE from the territorial and local levels jointly, and then affected ULUI. At the territorial level, traffic accessibility and urban image drastically improved with HSR; thus, can attract related production factors and boost related industries, finally resulting in ULE. At the local level, HSR station location was taken as a spatial supporting point for urban leapfrog development by local governments; thus, the land between downtown and HSR station was developed gradually. (2) HSR opening and HSR station distance from downtown had positive effects on ULE in China with elastic coefficients of $4.1 \%$ and $0.5 \%$, respectively. That was, HSR cities expanded $4.1 \%$ more than cities without HSR regarding urban land, and ULE increased by $0.5 \%$ for every $1 \%$ increase of HSR station distance. The effect of HSR opening on ULUI was not significant, while that of HSR station distance was significantly negative, that was, the farther away HSR station location, the lower the ULUI was, and specifically, for every $1 \%$ moving outward of HSR station, the inverse of ULUI increased by 7.3\%. (3) HSR opening and HSR station distance both had positive effects on the ULE of eastern, central region cities and big cities in China. However, for different regions and types of cities, HSR opening impact on ULUI was not significant, and only for the central region cities and small cities, HSR station distance had negative effect on ULUI. The following aspects deserve further study: first, the investigation of HSR impact on urban land- use structure; second, the spatial simulation of HSR impact on urban morphology with geo-computation model; third, the estimation of excessive ULE brought by HSR development; four, the investigation of HSR impacts on urban land-use efficiency; five, the evaluation of integration of HSR and urban land use with transit-oriented development (TOD) framework.

\section{Acknowledgements}

This work was supported by the Ministry of Education, Humanities, and Social Science Fund of China (19YJCZH089), the Natural Science Foundation of Jiangsu province (BK20191468) and the National Natural Science Foundation of China (41971221) 


\section{References}

Alonso, W. (1964). Location and land use. Cambridge, MA: Harvard University Press. http://doi. org/10.4159/harvard.9780674730854

Basse, R. M. (2013). A constrained cellular automata model to simulate the potential effects of highspeed train stations on land-use dynamics in trans-border regions. Journal of Transport Geography, 32, 23-37. http://doi.org/10.1016/j.jtrangeo.2013.08.005

Chen, C., \& Wei, B. (2013). High-speed rail and urban transformation in China: The case of Hangzhou East Rail Station. Built Environment, 39, 385-398. http://doi.org/10.2148/benv.39.3.385

Chen, Z., \& Haynes, K. E. (2015). Impact of high-speed rail on housing values: An observation from the Beijing-Shanghai line. Journal of Transport Geography, 43, 91-100. http://doi.org/10.1016/j. jtrangeo.2015.01.012

Chen, Z., \& Haynes, K. E. (2017). Impact of high-speed rail on regional economic disparity in China. Journal of Transport Geography, 65, 80-91. http://doi.org/10.1016/j.jtrangeo.2017.08.003

Chen, Z., Xue, J., Rose, A. Z., \& Haynes, K. E. (2016). The impact of high-speed rail investment on economic and environmental change in China: A dynamic CGE analysis. Transportation Research Part A: Policy and Practice, 92, 232-245. http://doi.org/10.1016/j.tra.2016.08.006

China State Council. (2011). National major function oriented zoning. Beijing: China State Council. (In Chinese). Retrieved from www.gov.cn/zhengce/content/2011-06/08/content_1441.htm

China State Council. (2016). To promote the rise of central China "13th five-year." Beijing: China State Council. (In Chinese). Retrieved from www.gov.cn/zhengce/content/2016-12/23/content_5151840.htm

Deng, T., Gan, C., Perl, A., \& Wang, D. (2020). What caused differential impacts on high-speed railway station area development? Evidence from global nighttime light data. Cities, 97, 102568. http:// doi.org/10.1016/j.cities.2019.102568

Deng, X., Huang, J., Rozelle, S., \& Uchida, E. (2008). Growth, population and industrialization, and urban land expansion of China. Journal of Urban Economics, 63(1), 96-115. http://doi.org/10.1016/j. jue.2006.12.006

Diao, M., Fan, Y., \& Zhang, X. (2019). Introduction to special issue: Rail transit development in China and beyond. Journal of Transport and Land Use, 12(1), 237-239. http://doi.org/10.5198/ jtlu.2019.1571

Diao, M., Zhu, Y., \& Zhu, J. (2016). Intra-city access to inter-city transport nodes: The implications of high-speed-rail station locations for the urban development of Chinese cities. Urban Studies, 54, 1-19. http://doi.org/10.1177/0042098016646686

Dong, L., Du, R., Kahn, M., Ratti, C., \& Zheng, S. (2020). “Ghost cities” versus boom towns: When do China's HSR new towns thrive? (Working paper). Retrieved from http://highspeedchina.org/pdf/ ghost_city.pdf.

Garmendia, M., Ribalaygua, C., \& Ureña, J. M. (2012). High speed rail: Implication for cities. Cities, 29, S26-S31. http://doi.org/10.1016/j.cities.2012.06.005

Glaeser, E. L., \& Kohlhase, J. E. (2003). Cities, regions and the decline of transport costs. Papers in Regional Science, 83, 197-228. http://dx.doi.org/10.2139/ssrn.431741

Harmon, R. (2006). High speed trains and the development and regeneration of cities. London: GreenGauge21. Retrieved from www.greengauge21.net/wp-content/uploads/hsr-regneration-of-cities.pdf Hopkins, F. M., Ehleringer, J. R., Bush, S. E., Duren, R. M., Miller, C. E., Lai, C.-T., .. Randerson, J. T. (2016). Mitigation of methane emissions in cities: How new measurements and partnerships can contribute to emissions reduction strategies. Earth's Future, 4(9), 408-425. http://doi.org/https:// doi.org/10.1002/2016EF000381 
Jiang, B., \& Ma, D. (2017). How complex is a fractal? Head/tail breaks and fractional hierarchy. Journal of Geovisualization \& Spatial Analysis, 2, 1-6. http://doi.org/10.1007/s41651-017-0009-z

Jiao, J., Wang, J., \& Jin, F. (2017). Impacts of high-speed rail lines on the city network in China. Journal of Transport Geography, 60, 257-266. http://doi.org/10.1016/j.jtrangeo.2017.03.010

Jiao, J., Wang, J., Zhang, F., Jin, F., \& Liu, W. (2020). Roles of accessibility, connectivity and spatial interdependence in realizing the economic impact of high-speed rail: Evidence from China. Transport Policy, 91, 1-15. http://doi.org/10.1016/j.tranpol.2020.03.001

Ke, X., van Vliet, J., Zhou, T., Verburg, P. H., Zheng, W., \& Liu, X. (2018). Direct and indirect loss of natural habitat due to built-up area expansion: A model-based analysis for the city of Wuhan, China. Land Use Policy, 74, 231-239. http://doi.org/10.1016/j.landusepol.2017.12.048

Khandker, S. R., Koolwal, G. B., \& Sammad, H. A. (2010). Handbook on impact, quantitative methods and practices. Washtington, DC: World Bank Publications. Retrieved from https://openknowledge. worldbank.org/handle/10986/2693

Li, H., Strauss, J., Shunxiang, H., \& Lui, L. (2018). Do high-speed railways lead to urban economic growth in China? A panel data study of China's cities. Quarterly Review of Economics and Finance, 69, 70-89. http://doi.org/10.1016/j.qref.2018.04.002

Li, X., Huang, B., Li, R., \& Zhang, Y. (2016). Exploring the impact of high-speed railways on the spatial redistribution of economic activities - Yangtze River Delta urban agglomeration as a case study. Journal of Transport Geography, 57, 194-206. http://doi.org/10.1016/j.jtrangeo.2016.10.011

Lichtenberg, E., \& Ding, C. (2009). Local officials as land developers: Urban spatial expansion in China. Journal of Urban Economics, 66(1), 57-64. http://doi.org/10.1016/j.jue.2009.03.002

Liu, Y., Fan, P., Yue, W., \& Song, Y. (2018). Impacts of land finance on urban sprawl in China: The case of Chongqing. Land Use Policy, 72, 420-432. http://doi.org/10.1016/j.landusepol.2018.01.004

Long, F., Zheng, L., \& Song, Z. (2018). High-speed rail and urban expansion: An empirical study using a time series of nighttime light satellite data in China. Journal of Transport Geography, 72, 106-118. http://doi.org/10.1016/j.jtrangeo.2018.08.011

Ministry of Land and Resources. (2008). Standard for evaluation of saving and intensive use of construction land. Beijing: Standards Press of China. (In Chinese). Retrieved from https://max.book118.com/ $\mathrm{html} / 2018 / 0210 / 152666511 . s h t m$

Mohino, I., Loukaitou-Sideris, A., \& Ureña, J. M. (2014). Impacts of high-speed rail on metropolitan integration: An examination of London, Madrid and Paris. International Planning Studies, 19(3-4), 1-29. http://doi.org/10.1080/13563475.2014.950638

Moser, P., \& Voena, A. (2009). Compulsory licensing: Evidence from the Trading with the Enemy Act. American Economic Review, 102, 396-427. http://dx.doi.org/10.2139/ssrn.1313867

NDRC. (2016). The medium-long term railway network plan of China. Beijing: National Development and Reform Commission. (In Chinese). Retrieved from www.gov.cn/xinwen/2016-07/20/content_5093165.htm

Peng, C., Song, M., \& Han, F. (2017). Urban economic structure, technological externalities, and intensive land use in China. Journal of Cleaner Production, 152, 47-62. http://doi.org/10.1016/j. jclepro.2017.03.020

Qu, F., Heerink, N., \& Wang, W. (1995). Land administration reform in China: Its impact on land allocation and economic development. Land Use Policy, 12(3), 193-203. http://doi.org/10.1016/02648377(95)00003-V

Shao, S., Tian, Z., \& Yang, L. (2017). High speed rail and urban service industry agglomeration: Evidence from China’s Yangtze River Delta region. Journal of Transport Geography, 64, 174-183. http:// doi.org/10.1016/j.jtrangeo.2017.08.019 
Shen, Y., De Abreu E Silva, J., \& Martínez, L. (2014). Assessing high-Speed Rail's impacts on land cover change in large urban areas based on spatial mixed logit methods: A case study of Madrid Atocha railway station from 1990 to 2006. Journal of Transport Geography, 41, 184-196. http://doi. org/10.1016/j.jtrangeo.2014.09.007

Shen, Y., Martínez, L., \& De Abreu E Silva, J. (2013). Impacts of short-term land use by high-speed rail on large metropolises. Transportation Research Record, 2374, 35-43. http://doi.org/10.3141/237405

Shen, Y., Martinez, L., \& De Abreu E Silva, J. (2014). Cellular agent-based approach incorporating spatial discrete choice methods simulation of future land-use impacts of high-speed rail on Aveiro, Portugal. Transportation Research Record, 2430, 105-115. http://doi.org/10.3141/2430-11

Shen, Y., Zhao, J., De Abreu E Silva, J., \& Martínez, L. (2017). From accessibility improvement to land development: A comparative study on the impacts of Madrid-Seville high-speed rail. Transportation Letters, 9, 1-15. http://doi.org/10.1080/19427867.2017.1286771

Shu, C., Xie, H., Jiang, J., \& Chen, Q. (2018). Is urban land development driven by economic development or fiscal revenue stimuli in China? Land Use Policy, 77, 107-115. http://doi.org/10.1016/j. landusepol.2018.05.031

Tan, R., Qu, F., Heerink, N., \& Mettepenningen, E. (2011). Rural to urban land conversion in China - How large is the over-conversion and what are its welfare implications? China Economic Review, 22(4), 474-484. http://doi.org/10.1016/j.chieco.2011.07.013

Tranos, E. (2012). The causal effect of the internet infrastructure on the economic development of European city regions. Spatial Economic Analysis, 7, 319-337. http://doi.org/10.1080/17421772.2 012.694140

UIC. (2011). High speed rail as a tool for regional development. Frankfurt: International Union of Railways, DB International GmbH. Retrieved from www.ave-altavelocidad.es/avecedario/pdf/U/HighSpeedRail_RegionalDevelopment.pdf

Ureña, J. M., Menerault, P., \& Garmendia, M. (2009). The high-speed rail challenge for big intermediate cities: A national, regional and local perspective. Cities, 26(5), 266-279. http://doi.org/10.1016/j. cities.2009.07.001

Wang, D., Wang, L., Chen, T., Lu, L., Niu, Y., \& Alan, A. L. (2016). HSR mechanisms and effects on the spatial structure of regional tourism in China. Journal of Geographical Sciences, 26(12), 17251753. http://doi.org/10.1007/s11442-016-1355-3

Wang, J., Du, D., \& Huang, J. (2020). Inter-city connections in China: High-speed train vs. inter-city coach. Journal of Transport Geography, 82, 102619. http://doi.org/10.1016/j.jtrangeo.2019.102619

Wang, S., Wang, J., \& Liu, X. (2019). How do urban spatial structures evolution in the high-speed rail era? Case study of Yangtze River Delta, China. Habitat International, 93, 102051. htpp://doi. org/10.1016/j.habitatint.2019.102051

Wang, X., Huang, S., Zou, T., \& Yan, H. (2012). Effects of the high-speed rail network on China's regional tourism development. Tourism Management Perspectives, 1, 34-38. http://doi.org/10.1016/j. tmp.2011.10.001

Willigers, J., \& van Wee, B. (2011). High-speed rail and office location choices. A stated choice experiment for the Netherlands. Journal of Transport Geography, 19(4), 745-754. http://doi.org/10.1016/j. jtrangeo.2010.09.002

Wu, Y., Luo, J., Zhang, X., \& Skitmore, M. (2016). Urban growth dilemmas and solutions in China: Looking forward to 2030. Habitat International, 56, 42-51. http://doi.org/10.1016/j.habitatint.2016.04.004

Wu, Y., Zhang, X., Skitmore, M., Song, Y., \& Hui, E. C. M. (2014). Industrial land price and its impact 
on urban growth: A Chinese case study. Land Use Policy, 36, 199-209. http://doi.org/10.1016/j. landusepol.2013.08.015

Yin, M., Bertolini, L., \& Duan, J. (2015). The effects of the high-speed railway on urban development: International experience and potential implications for China. Progress in Planning, 98, 1-52. http:// doi.org/10.1016/j.progress.2013.11.001

Zhang, G., Zheng, D., Wu, H., Wang, J., \& Li, S. (2020). Assessing the role of high-speed rail in shaping the spatial patterns of urban and rural development: A case of the Middle Reaches of the Yangtze River, China. Science of The Total Environment, 704, 135399. http://doi.org/10.1016/j.scitotenv.2019.135399

Zheng, L., Long, F., Chang, Z., \& Ye, J. (2019). Ghost town or city of hope? The spatial spillover effects of high-speed railway stations in China. Transport Policy, 81, 230-241. http://doi.org/10.1016/j. tranpol.2019.07.005 